\title{
Inosine at Different Primer Positions to Study Structure and Diversity of Prokaryotic Populations
}

\author{
Eitan Ben-Dov*1,2 and Ariel Kushmaro ${ }^{2,3}$ \\ ${ }^{1}$ Department of Life Sciences, Achva Academic College, \\ MP Shikmim, 79800, Israel \\ 2Department of Biotechnology Engineering and National \\ Institute for Biotechnology in the Negev, Ben-Gurion \\ University of the Negev, PO Box 653, Be'er-Sheva, 84105, \\ Israel \\ ${ }^{3}$ School of Materials Science and Engineering, Nanyang \\ Technological University, Singapore 637819 (Singapore). \\ *Corresponding author: etn@bgu.ac.il \\ DOI: http://dx.doi.org/10.21775/cimb.017.053
}

\begin{abstract}
Culture-independent methods, employed to study the diversity and complexity of microbial communities that are based on amplification of rRNA genes with universal primers, include gradient gel electrophoresis (denaturing or temperature), single-strand-conformation polymorphism, restriction fragment length polymorphism, qPCR and highthroughput DNA sequencing. Substituting one or more base(s) within or at the 3'-termi of the universal primers by inosine can overcome some of their shortcomings improving amplification capacity. Universal primer sets do not usually amplify sequences with nucleotide mismatch to the templates, particularly in the last three bases, whereas inosine-modified primers anneal and amplify a variety of rRNA gene sequences. Inosine-containing primers are therefore might be useful to detect more species in diverse prokaryotic populations. The article summarizes the pros and cons of using inosine especially at the 3 ' termini of universal primers in nucleic acid amplification for the study of microbial diversity.
\end{abstract}

\section{Introduction}

Phylogenetic analysis and study of prokaryotic diversity based on 16S rRNA gene comparison (Woese and Fox, 1977 ) was enhanced by discovery of the PCR (Weisburg, et al., 1991). Culture-independent methods are advantageous to investigate the occurrence and distribution of bacteria in nature, providing direct information on community structure (Daly et al., 2000; Steven et al., 2007; Su et al., 2012). Most of these studies require extraction of total bacterial DNA from the sample and PCR amplification of one of the rRNA genes using universal primers designed according to their conserved sequences. This approach is straightforward, but biased at almost all steps: DNA extraction, primers selection and amplification (Bru et al., 2008; Fujiwara et al., 1995; Hansen et al., 1998; MartinLaurent et al., 2001; Polz and Cavanaugh, 1998; Suzuki and Giovanni, 1996; Wu et al., 2009), producing an incomplete and often distorted view (Forney et al., 2004) of the community structure.
The choice of universal 16S rRNA gene primers used in studies to assess the diversity of prokaryotes is not trivial becouse (Baker et al., 2003; Forney et al., 2004): (a) complementarity to a large fraction of the sequences in databases such as the ribosomal database project [RDP; (Cole et al., 2009)] are not necessarily optimal; (b) sequences in the database may be incomplete or ambiguous; (c) no current data base faithfully represents the estimated total number of over 10 million bacterial species, with possible high sequence divergence (Curtis et al., 2002; Winsley et al., 2012). Efforts are therefore being made to improve universality of the primers.

\section{Substituting canonical bases by inosine}

Inosine is identical to guanine lacking the N2 amino group. It is found in the 5'-nucleotide of tRNA anticodons of mRNA, known as Watson-Crick wobble position, when different triplets encode the same amino acid (Crick, 1966), and loosely pairs to either cytosine, adenosine or uridine. Inosine's annealing intensities to the four nucleotides depends on the thermodynamic stabilities of the pairings (Martin et al., 1985; Watkins and SantaLucia, 2005). Nevertheless, it is successfully used in a variety of PCR primers and probes that require degeneracy such as at the wobble position, to permit annealing to different but closely related sequences (Candrian et al., 1991; Ohtsuka et al., 1985). The annealing temperature and the composition of reaction mixtures can be manipulated to achieve better universality of such inosine containing primers. The presence of inosine in an oligonucleotide seems to neither disturb nor destabilize DNA duplex formation (Ohtsuka et al., 1985). Replacing inosine (I) in degenerate primers often yields amplification results superior than of the mixedbase degenerate primers (Liu and Nichols, 1994). In internal positions of synthetic oligonucleotides, pairing of I to thymine $(T)$ or guanine $(G)$ reduces the hybrid yield 10-30 fold and to a lesser extent to adenine (A) over its pairing to cytosine (C) (Case-Green and Southern, 1994). The order of stabilities of paired-inosine is: $I \cdot C>I \cdot A>I \cdot T \approx$ I.G > I.I (Martin et al., 1985); it is thus the favorite base to replace two (G/T, G/A, T/A), three or four base ambiguities. At the 3 '-end, I pairs preferentially in the same order, albeit with reduced discrimination between the four bases, but at the 5'-end, it shows the same signal strength when paired against each of them (Case-Green and Southern, 1994).

The hierarchy of hybridization yields of an octamer with two adjacent l's in the center is $C C>C A>A A>A C>$ $\mathrm{GC}>\mathrm{GA}>\mathrm{CG}>\mathrm{TA}>\mathrm{TC}>\mathrm{CT}=\mathrm{AG}>\mathrm{AT}>\mathrm{GT}>\mathrm{TT}$ (Case-Green and Southern, 1994). A neighboring pair has large influence on the stability of $\mathrm{I} \cdot \mathrm{N}$ base pair at the $5^{\prime}-$ or 3'-end of an oligonucleotide with the following tendency's hierarchy: $\mathrm{G} \cdot \mathrm{C}>\mathrm{C} \cdot \mathrm{G}>\mathrm{A} \cdot \mathrm{T}>\mathrm{T} \cdot \mathrm{A}$, reflecting a complex interplay between $\mathrm{H}$-bonding, nearest-neighbor stacking and mismatch geometry (Watkins and SantaLucia, 2005). 
This information may be useful in designing a primer/probe of optimal stability (Martin et al., 1985; Watkins and SantaLucia, 2005) to enhance primer universality while retaining specificity. While these parameters can be modulated in an attempt to increase universality, it is likely to be accompanied by a tradeoff in specificity so that nontarget sequences are also amplified (Forney et al., 2004).

\section{Utility of inosine in culture-independent methods}

Inosine at internal primer positions

Two types of primers are used to enhance their universality for amplification of related sequences from different species having more than one nucleotide at a given location: degenerate primers or those containing I (Kilpatrick et al., 1996; Rossolini et al., 1994; Wu et al., 2009). Replacing a wobble-position base by I substantially reduces unspecific annealing of degenerate primer sets commonly used for amplification of protein-coding or of highly-conserved (e.g., of rRNA) genes.

Introducing residues of $\mathrm{I}$ into the core of universal primers homologous to conserved regions in the $16 \mathrm{~S}$ rRNA genes, for example, enabled amplification and detection of phylotypes that were not detected using the original, unmodified primers (Watanabe et al., 2001). Such primers were used in analyses of microbial diversity of oil palm rhizosphere (Acevedo et al., 2014), cattle manure and anode biofilms (Inoue et al., 2013). I-containing primers for different types of human papillomavirus yield higher amounts and more specific amplicons than the corresponding degenerate primers (Rossolini et al., 1994). Internally-placed I in primers for $16 \mathrm{~S}$ rRNA were recently used in next-generation DNA sequencing to catalog bacterial reads within complex, polymicrobial specimens (Salipante et al., 2013).

A large proportion of commonly used universal primers for $16 \mathrm{~S}$ rRNA genes lack sequence homology to many of the "candidate" divisions, severely limiting bacterial variety assessments (Winsley et al., 2012) and thus display diverse coverage rates (Wang and Qian, 2009). So-called "conserved regions" in the $16 S$ rDNA used as universal primers include many mismatches in the core (Watanabe et al., 2001; Thomas et al., 2011) and less in their 3'-end (Ben-Dov et al., 2011; Brands et al., 2010).

Inosine at the 3'-end of primers

Inclusion of degenerate bases or I at the 3 '-end is usually considered undesirable because incompatible annealing of the ultimate or penultimate base(s) can suffice to initiate PCR at wrong sites (White, 1993). On the other hand, mismatched nucleotides at these positions may be detrimental to the amplification process (Kwok et al., 1990; Sarkar et al., 1990; Wu et al., 2009) because loose primer hybridization affects binding stability of the DNA polymerase to a primer-template terminus (Detera et al., 1981; Huang et al., 1992; Kamtekar et al., 2006). This is primarily due to a need for a perfect 3'-end base pair to allow enzymatic synthesis (Batzer et al., 1991). A point mutation at this position in the template will therefore have a much greater effect than mutations in neighboring bases.

Inclusion of I at the 3'-end position in PCR primers of the Alu family, seminally performed by Batzer at al. (1991), resulted in a $150 \mathrm{bp}$ amplicon from green monkey DNA, which was not amplified using identical primers without I. Using I at the 3'-termini of universal primers for 16S rDNA to study microbial diversity discovered 7 bacterial phyla whereas the original set amplified sequences belonging almost exclusively to Proteobacteria (Ben-Dov et al., 2006). I-substituted universal primers for 16S rDNA at the 3'termini were used successfully in analyses of microbial diversity from different environmental niches such as industrial wastewater (Shapiro et al., 2009), coral black band diseases microbial mats (Barneah et al., 2007), desert soil (Angel et al., 2009), grapevine leaves (Bulgari et al., 2009), human feces (Patil et al., 2012; Zheng et al., 2009), oral plaque biofilms (Brands et al., 2010), hot spring ecosystems (Valverde et al., 2012) and gut flora of sand flies (Mukhopadhyay et al., 2012). This increased diversity confirms the usefulness of I-containing 3'-termini primerpairs to expand the observed diversity of microbial communities but is not guaranteed to amplify all species existing in the examined sample.

An additional approach to obtain expanded microbial diversity uses substitutions of the two last bases at the 3'end of each of the primers by two inosines (Ben-Dov et al., 2011). This primer-pair expands somewhat the observed diversity of a bacterial community at the family/class level, but significantly shifts the composition of the resulting $16 \mathrm{~S}$ rDNA libraries from that obtained by two other primer-pairs, one with a single I substitution at the 3 '-end and the other with no substitution. The most obvious shift in composition came with the detection of a higher abundance of sequences related to the class Clostridia. When two I's substituted AG in the two last 3 '-end bases of the forward primer, the resulting hybridization (I-T-I.C) apparently destabilized primer-template-polymerase complex, and since the base adjacent to the 3 '-end in the 16S rDNA of Clostridia's template contains a high frequency of G's $(98.8 \%)$ the formation of first pairing $(C \cdot G)$ by Taq polymerase stabilized the initial amplification efficiency and thus biased it toward this class (Ben-Dov et al., 2011).

The base adjacent to the 3 '-end of universal PCR primers targeting $16 \mathrm{~S}$ rDNA is variable and thus impacts the initial phase of PCR amplification: A or T decrease PCR efficiency whereas $\mathrm{G}$ or $\mathrm{C}$ stabilize primer-templateenzyme-nucleotide complex and thus increase amplification rates (Ben-Dov et al., 2012). I-modified primers preferentially (but not exclusively) amplify sequences containing $\mathrm{G}$ or $\mathrm{C}$ next to the 3 '-end of the primer over sequences containing $\mathrm{A}$ or $\mathrm{T}$ (Brands et al., 2010). Such next-base effects can distort data used to draw conclusions about structures of microbial communities in a PCR-based approach, due to bias in estimating the relative ratios between phylotypes having different template-contiguous bases to the $3^{\prime}$ end primers (Ben-Dov et al., 2012).

\section{Concluding remarks}

High-throughput or 'next generation' DNA sequencing platforms dramatically increase sequencing depth of phylogenetic analyses of explored microbial communities, but limitation in universality of commonly used primers can still provide only a narrow view of these communities. PCR amplification of DNA is a key preliminary step in many applications of high-throughput sequencing technologies, 
yet design and taxonomic analysis of novel universal or near-universal primers remains a challenging task (Walters et al., 2011). Universal primers containing inosine can reveal more varied templates and thus expand the observed diversity of microbial communities, but does not necessarily amplify all heterologous sequences of different species existing in explored niches. The importance of adopting multiple approaches to design universal primers for PCR analyses to assess microbial biota in complex environments is emphasized and substantiated.

\section{Acknowledgements}

This work was supported by research funds from the Ramat-Hovav Council. Arieh Zaritsky is gratefully acknowledged for the thorough scrutiny of the manuscript and for his critical and helpful comments.

\section{References}

Acevedo, E., Galindo-Castañeda, T., Prada, F., Navia, M., and Romero, H.M. (2014). Phosphate-solubilizing microorganisms associated with the rhizosphere of oil palm (Elaeis guineensis Jacq.) in Colombia. Appl. Soil Ecol. 80, 26-33.

Angel, R., Soares, M.I.M., Ungar, E.D., and Gillor, O. (2009). Biogeography of soil archaea and bacteria along a steep precipitation gradient. ISME J. 4, 553-563.

Baker, G.C., Smith, J.J., and Cowan, D.A. (2003). Review and re-analysis of domain-specific $16 \mathrm{~S}$ primers. J. Microbiol. Methods 55, 541-555.

Barneah, O., Ben-Dov, E., Kramarsky-Winter, E., and Kushmaro, A. (2007). Characterization of black band disease in Red Sea stony corals. Environ. Microbiol. 9, 1995-2006.

Batzer, M.A., Carlton, J.E., and Deininger, P.L. (1991). Enhanced evolutionary PCR using oligonucleotides with inosine at the 3'-terminus. Nucleic Acids Res. 19, 5081.

Ben-Dov, E., Shapiro, O.H., and Kushmaro, A. (2012). 'Next-base'effect on PCR amplification. Environ. Microbiol. Rep. 4, 183-188.

Ben-Dov, E., Shapiro, O.H., Siboni, N., and Kushmaro, A. (2006). Advantage of using inosine at the $3^{\prime}$ termini of $16 \mathrm{~S}$ rRNA gene universal primers for the study of microbial diversity. Appl. Environ. Microbiol. 72, 69026906.

Ben-Dov, E., Siboni, N., Shapiro, O.H., Arotsker, L., and Kushmaro, A. (2011). Substitution by inosine at the 3'ultimate and penultimate positions of 16S rRNA gene universal primers. Microb. Ecol. 61, 1-6.

Brands, B., Vianna, M.E., Seyfarth, I., Conrads, G., and Horz, H.P. (2010). Complementary retrieval of16S rRNAgene sequences using broad-range primers with inosine at the 3'-terminus: implications for the study of microbial diversity. FEMS Microbiol. Ecol. 71, 157-167.

Bru, D., Martin-Laurent, F., and Philippot, L. (2008). Quantification of the detrimental effect of a single primer - template mismatch by real-time PCR using the $16 \mathrm{~S}$ rRNA gene as an example. Appl. Environ. Microbiol. 74, 1660-1663.

Bulgari, D., Casati, P., Brusetti, L., Quaglino, F., Brasca, M., Daffonchio, D., and Bianco, P. A. (2009). Endophytic bacterial diversity in grapevine (Vitis vinifera L.) leaves described by $16 \mathrm{~S}$ rRNA gene sequence analysis and length heterogeneity-PCR. J. Microbiol. 47, 393-401.

Candrian, U., Furrer, B., Hofelein, C., and Luthy, J. (1991). Use of inosine-containing oligonucleotide primers for enzymatic amplification of different alleles of the gene coding for heat-stable toxin type I of enterotoxigenic Escherichia coli. Appl. Environ. Microbiol. 57, 955-961.

Case-Green, S.C., and Southern, E.M. (1994). Studies on the base pairing properties of deoxyinosine by solid phase hybridisation to oligonucleotides. Nucleic Acids Res. 22, 131-136.

Cole, J.R., Wang, Q., Cardenas, E., Fish, J., Chai, B., Farris, R.J., Kulam-Syed-Mohideen, A.S., McGarrell, D.M., Marsh, T., Garrity, G.M., et al. (2009). The Ribosomal Database Project: improved alignments and new tools for rRNA analysis. Nucleic Acids Res. 37, D141-D145.

Crick, F.H.C. (1966). Codon-anticodon pairing: the wobble hypothesis. J Mol Biol 19, 548-555.

Curtis, T.P., Sloan, W.T., and Scannell, J.W. (2002). Estimating prokaryotic diversity and its limits. Proc. Natl. Acad. Sci. USA 99, 10494-10499.

Daly, K., Sharp, R.J., and McCarthy, A.J. (2000). Development of oligonucleotide probes and PCR primers for detecting phylogenetic subgroups of sulfate-reducing bacteria. Microbiology 146, 1693-1705.

Detera, S.D., Becerra, S.P., Swack, J.A., and Wilson, S.H. (1981). Studies on the Mechanism of DNA Polymerase alpha. J. Biol. Chem. 256, 6933-6943.

Forney, L.J., Zhou, X., and Brown, C.J. (2004). Molecular microbial ecology: land of the one-eyed king. Curr. Opin. Microbiol. 7, 210-220.

Fujiwara, H., Fujiwara, K., and Hashimoto, K. (1995). PCR with deoxyinosine-containing primers using DNA polymerases with proofreading activity. Genome Res. 4, 239-240.

Hansen, M.C., Tolker-Neilson, T., Givskov, M., and Molin, S. (1998). Biased $16 S$ rDNA PCR amplication caused by interference from DNA flanking template region. FEMS Microbiol. Ecol. 26, 141-149.

Huang, M.M., Arnheim, N., and Goodman, M.F. (1992). Extension of base mispairs by Taq DNA polymerase: implications for single nucleotide discrimination in PCR. Nucleic Acids Res. 20, 4567-4573.

Inoue, K., Ito, T., Kawano, Y., Iguchi, A., Miyahara, M., Suzuki, Y., and Watanabe, K. (2013). Electricity generation from cattle manure slurry by cassetteelectrode microbial fuel cells. J. Biosci. Bioeng. 116, 610-615.

Kamtekar, S., Berman, A.J., Wang, J., Lázaro, J.M., de Vega, M., Blanco, L., Salas, M., and Steitz, T.A. (2006). The $\varphi 29$ DNA polymerase: protein-primer structure suggests a model for the initiation to elongation transition. EMBO J. 25, 1335-1343.

Kilpatrick, D.R., Nottay, B., Yang, C.-F., Yang, S.-J., Mulders, M.N., Holloway, B.P., Pallansch, M.A., and Kew, O.M. (1996). Group-specific identification of polioviruses by PCR using primers containing mixedbase or deoxyinosine residues at positions of codon degeneracy. J. Clin. Microbiol. 34, 2990-2996.

Kwok, S., Kellogg, D.E., McKinney, N., Spasic, D., Goda, L., Levenson, C., and Sninsky, J.J. (1990). Effects of 
primer-template mismatches on the polymerase chain reaction: human immunodeficiency virus type 1 model studies. Nucleic Acids Res. 18, 999-1005.

Liu, H., and Nichols, R. (1994). PCR amplification using deoxyinosine to replace an entire codon and at ambiguous positions. Biotechniques 16, 24-26.

Martin, F.H., Castro, M.M., Aboul-ela, F., and Tinoco, I. (1985). Base pairing involving deoxyinosine: implications for probe design. Nucleic Acids Res. 13, 8927-8938.

Martin-Laurent, F., Philippot, L., Hallet, S., Chaussod, R., Germon, J.C., Soulas, G., and Catroux, G. (2001). DNA extraction from soils: Old bias for new microbial diversity analysis methods. Appl. Environ. Microbiol. 67, 23542359.

Mukhopadhyay, J., Braig, H.R., Rowton, E.D., and Ghosh, K. (2012). Naturally occurring culturable aerobic gut flora of adult Phlebotomus papatasi, vector of Leishmania major in the Old World. PLoS One 7, e35748.

Ohtsuka, E., Matsuki, S., Ikehara, M., Takahashi, Y., and Matsubara, K. (1998). An alternative approach to deoxyoligonucleotides as hybridization probes by insertion of deoxyinosine at ambiguous codon positions. J. Biol. Chem. 260, 2605-2608.

Patil, D.P., Dhotre, D.P., Chavan, S.G., Sultan, A., Jain, D.S., Lanjekar, V.B., Gangawani, J., Shah, P.S., Todkar, J.S., Shah, S., et al. (2012). Molecular analysis of gut microbiota in obesity among Indian individuals. J. Biosci. 37, 647-657.

Polz, M.F., and Cavanaugh, C.M. (1998). Bias in templateto-product ratios in multi-template PCR. Appl. Environ. Microbiol. 64, 3724-3730.

Rossolini, G.M., Cresti, S., Ingianni, A., Cattani, P., Riccio, M.L., and Satta, G. (1994). Use of deoxyinosinecontaining primers vs degenerate primers for polymerase chain reaction based on ambiguous sequence information. Mol. Cell Probes 8, 91-98.

Salipante, S.J., SenGupta, D.J., Hoogestraat, D.R., Cummings, L.A., Bryant, B.H., Natividad, C., Thielges, S., Monsaas, P.W., Chau, M., Barbee, L.A., et al. (2013). Molecular diagnosis of Actinomadura madurae infection by $16 \mathrm{~S}$ rRNA deep sequencing. J. Clin. Microbiol. 51, 4262-4265.

Sarkar, G., Cassady, J., Bottema, C.D.K., and Sommer S.S. (1990). Characterization of polymerase chain reaction amplification of specific alleles. Anal. Biochem. 186, 64-68.

Shapiro, O.H., Kushmaro, A., and Brenner, A. (2009). Bacteriophage predation regulates microbial abundance and diversity in a full-scale bioreactor treating industrial wastewater. ISME J. 4, 327-336.

Steven, B., Briggs, G., McKay, C.P., Pollard, W.H., Greer, C.W., and Whyte, L.G. (2007). Characterization of the microbial diversity in a permafrost sample from the Canadian high Arctic using culture-dependent and culture-independent methods. FEMS Microbiol. Ecol. 59, 513-523.

Su, C., Lei, L., Duan, Y., Zhang, K.Q., and Yang, J. (2012). Culture-independent methods for studying environmental microorganisms: methods, application, and perspective. Appl. Microbiol. Biotechnol. 93, 993-1003.

Suzuki, M.T., and Giovanni, S.J. (1996). Bias caused by template annealing in the amplification of mixtures of $16 \mathrm{~S}$ rRNA genes by PCR. Appl. Environ. Microbiol. 62, 625630.

Thomas, M.C., Thomas, D.K., Selinger, L.B., and Inglis, G.D. (2011). SPYDER, a new method for in silico design and assessment of $16 \mathrm{~S}$ rRNA gene primers for molecular microbial ecology. FEMS Microbiol. Lett. 320, 152-159.

Valverde A., Tuffin, M., and Cowan, D.A. (2012). Biogeography of bacterial communities in hot springs: a focus on the actinobacteria. Extremophiles 16, 669-679.

Walters, W.A., Caporaso, J.G., Lauber, C.L., Berg-Lyons, D., Fierer, N., and Knight, R. (2011). PrimerProspector: de novo design and taxonomic analysis of barcoded polymerase chain reaction primers. Bioinformatics 27 , 1159-1161.

Wang, Y., and Qian, P.Y. (2009). Conservative fragments in bacterial 16S rRNA genes and primer design for 16S ribosomal DNA amplicons in metagenomic studies. PLoS One 4, e7401.

Watanabe, K., Kodama, Y., and Harayama, S. (2001). Design and evaluation of PCR primers to amplify $16 S$ ribosomal DNA fragments used for community fingerprinting. J. Microbiol. Methods 44, 253-262.

Watkins, N.E., and SantaLucia, J. (2005). Nearest-neighbor thermodynamics of deoxyinosine pairs in DNA duplexes. Nucleic Acids Res. 33, 6258-6267.

Weisburg, W.G., Barns, S.M., Pelletier, D.A., and Lane, D.J. (1991). 16S ribosomal DNA amplification for phylogenetic study. J. Bacteriol. 173, 697-703.

White, B.A. (1993). PCR Protocols, Current Methods and Applications. (Humana Press, Totowa, New Jersey).

Winsley, T., Van Dorst, J.M., Brown, M.V., and Ferrari, B.C. (2012). Capturing greater 16S rRNA gene sequence diversity within the domain bacteria. Appl. Environ. Microbiol. 78, 5938-5941.

Woese, C.R., and Fox, G.E. (1977). Phylogenetic structure of the prokaryotic domain: the primary kingdoms. Proc. Natl. Acad. Sci. USA 74, 5088-5090.

Wu, J.H., Hong, P.Y., and Liu, W.T. (2009). Quantitative effects of position and type of single mismatch on single base primer extension. J. Microbiol. Methods 77, 267275.

Zheng, G., Yampara-lquise, H., Jones, J.E., and Carson, A. (2009). Development of Faecalibacterium 16S rRNA gene marker for identification of human faeces. J. Appl. Microbiol. 106, 634-641. 


\section{Microbiology / Molecular Biology}

Caister Academic Press is a leading academic publisher of advanced texts in microbiology, molecular biology and medical research. Full details of all our publications at caister.com

- Cyanobacteria: Omics and Manipulation Edited by: DA Los (2017) www.caister.com/cyano3

- Brain-eating Amoebae: Biology and Pathogenesis of Naegleria fowleri

Author: R Siddiqui, IKM Ali, JR Cope, et al. (2016)

"explains the current knowledge and research" (ProtoView) www.caister.com/naegleria

- Foot and Mouth Disease Virus: Current Research and Emerging Trends

Edited by: F Sobrino, E Domingo (2017)

www.caister.com/fmdv

- Staphylococcus: Genetics and Physiology

Edited by: GA Somerville (2016)

www.caister.com/staph2

- Chloroplasts: Current Research and Future Trends Edited by: H Kirchhoff (2016)

www.caister.com/chloroplasts

- Microbial Biodegradation: From Omics to Function and Application

Edited by: J Długoński (2016)

www.caister.com/biodegradation

- Influenza: Current Research

Edited by: Q Wang, YJ Tao (2016)

www.caister.com/flu3

- MALDI-TOF Mass Spectrometry in Microbiology Edited by: M Kostrzewa, S Schubert (2016)

www.caister.com/malditof

- Aspergillus and Penicillium in the Post-genomic Era Edited by: RP Vries, IB Gelber, MR Andersen (2016)

"new and well-presented book" (IMA Fungus)

www.caister.com/aspergillus2

- The Bacteriocins: Current Knowledge and Future

Prospects

Edited by: RL Dorit, SM Roy, MA Riley (2016)

www.caister.com/bacteriocins

- Omics in Plant Disease Resistance

Edited by: V Bhadauria (2016)

"essential reading ... highly recommended" (Biotechnol. Agron.

Soc. Environ.)

www.caister.com/opdr

- Acidophiles: Life in Extremely Acidic Environments

Edited by: R Quatrini, DB Johnson (2016)

"Contributors from a wide range of biological and environmental sciences" (ProtoView)

www.caister.com/acidophiles
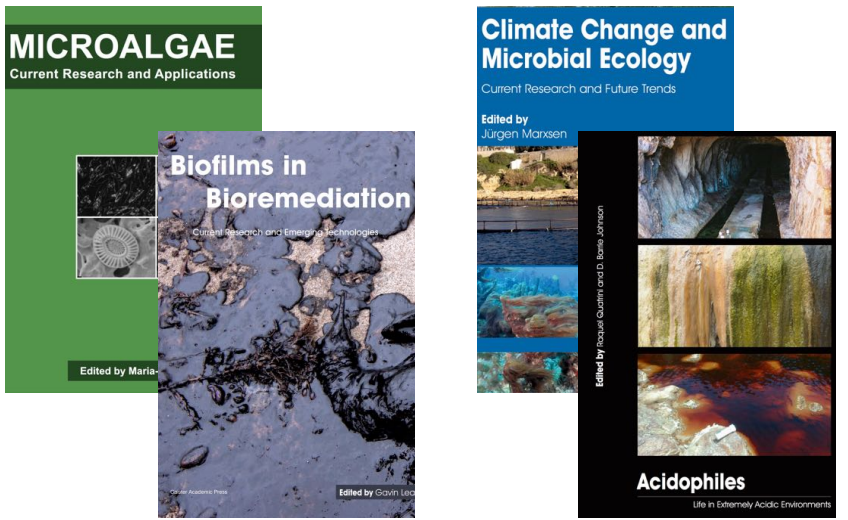
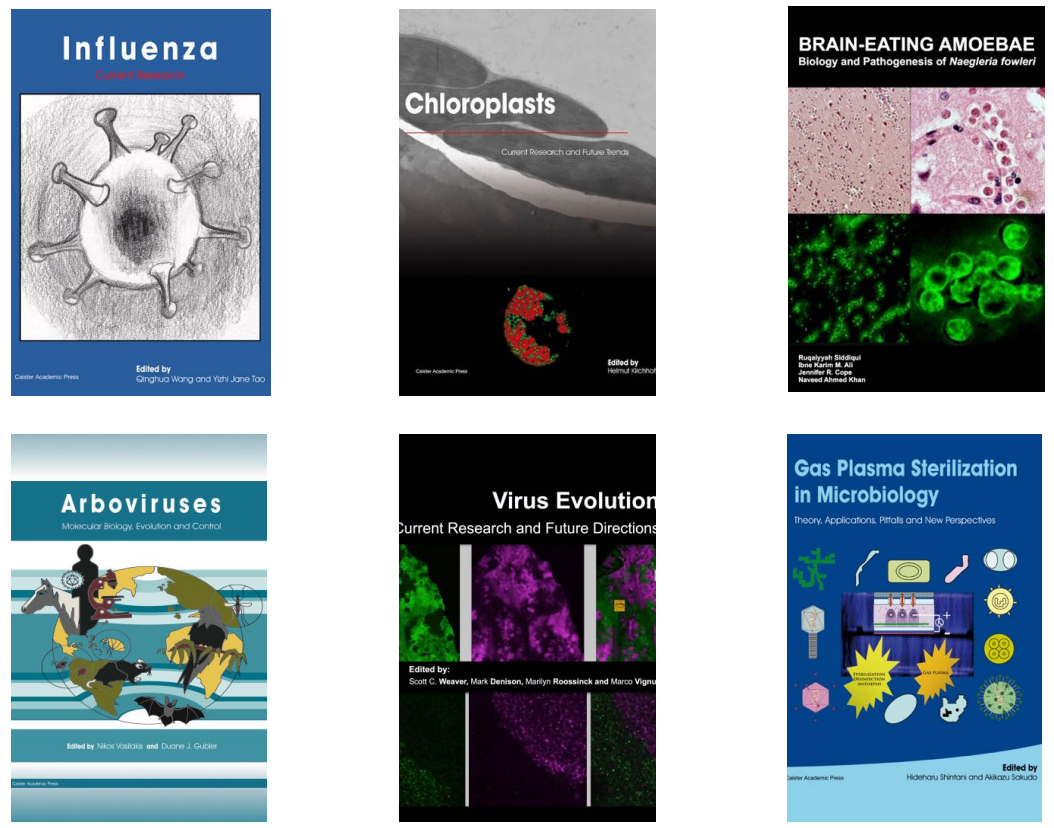

- Climate Change and Microbial Ecology: Current Research and Future Trends

Edited by: J Marxsen (2016)

"impressive" (ASM: Small Things Considered); "written at a high scientific level" (BioSpektrum)

www.caister.com/climate

- Biofilms in Bioremediation: Current Research and Emerging Technologies

Edited by: G Lear (2016)

"describes explicitly the role of biofilms in bioremediation" (Biospektrum); indispensable ... recommended (Biotechnol. Agron. Soc. Environ.) www.caister.com/biorem

- Microalgae: Current Research and Applications

Edited by: MN Tsaloglou (2016)

www.caister.com/microalgae

- Gas Plasma Sterilization in Microbiology: Theory, Applications, Pitfalls and New Perspectives

Edited by: H Shintani, A Sakudo (2016)

"a nice state of the art compilation" (Doodys)

www.caister.com/gasplasma

- Virus Evolution: Current Research and Future Directions Edited by: SC Weaver, M Denison, M Roossinck, et al. (2016) "highly informative ... a pleasure to read" (Microbiol. Today) www.caister.com/virusevol

- Arboviruses: Molecular Biology, Evolution and Control Edited by: N Vasilakis, DJ Gubler (2016)

"a thorough and compelling review ... an outstanding book ... highly recommended" (Am. J. Trop. Med. Hyg.) www.caister.com/arbo

- Shigella: Molecular and Cellular Biology

Edited by: WD Picking, WL Picking (2016)

www.caister.com/shigella

- Aquatic Biofilms: Ecology, Water Quality and Wastewater Treatment

Edited by: AM Romaní, H Guasch, MD Balaguer (2016)

"essential reference book" (Biotechnol. Agron. Soc. Environ.)

www.caister.com/aquaticbiofilms

- Alphaviruses: Current Biology

Edited by: S Mahalingam, L Herrero, B Herring (2016)

"up-to-date review of the field" (Aus. Vet. J.)

www.caister.com/alpha 